\title{
A Multidimensional Approach to the Study of Human- Information Interaction: A Case Study of Collaborative Information Retrieval
}

\author{
Raya Fidel \\ Center for Human-Information Interaction, The Information School, Box 352840, University of Washington, \\ Seattle, WA 98195. E-mail: Fidelr@u.washington.edu \\ Annelise Mark Pejtersen and Bryan Cleal \\ Cognitive Systems Engineering Center, Systems Analysis Department, Risoe National Laboratory, \\ Frederiksborgvej 399, DK 4000 Roskilde, Denmark. E-mail: \{annelise.mark.pejtersen, bryan.cleal\}@risoe.dk
}

\author{
Harry Bruce \\ The Information School, Box 352840, University of Washington, Seattle, WA 98195. \\ E-mail: harryb@u.washington.edu
}

\begin{abstract}
While most research in the area of human-information behavior has focused on a single dimension - either the psychological or the social-this case study demonstrated the importance of a multidimensional approach. The Cognitive Work Analysis framework guided this field study of one event of collaborative information retrieval (CIR) carried out by design engineers at Microsoft, including observations and interviews. Various dimensions explained the motives for this CIR event and the challenges the participants encountered: the cognitive dimension, the specific task and decision, the organization of the teamwork, and the organizational culture. Even though it is difficult at times to separate one dimension from another, and all are interdependent, the analysis uncovered several reasons for design engineers to engage in CIR, such as when they are new to the organization or the team, when the information lends itself to various interpretations, or when most of the needed information is not documented. Similar multidimensional studies will enhance our understanding of human-information behavior.
\end{abstract}

The last two decades have seen an increased interest in the study of human-information behavior. In addition to a rise in the number of user studies, the field has experienced a growth in theoretical development that has introduced new conceptual frameworks and expanded on existing ones (Pet-

Received July 1, 2003; revised October 10, 2003; accepted November 20, 2003

(C) 2004 Wiley Periodicals, Inc. • Published online 4 May 2004 in Wiley InterScience (www.interscience.wiley.com). DOI: 10.1002/asi.20041 tigrew, Fidel, \& Bruce, 2001). Various objectives have directed conceptual research in information behavior. Parts of it aimed at developing theories and concepts that would guide research in this area (e.g., Bates, 1989; Ellis, 1989; Pettigrew, 2000; Wilson, 1999), and other parts tested whether theories borrowed from other fields can bring new insights (e.g., Chatman, 2000; Kuhlthau, 1991; Tuominen \& Savolainen, 1997). Of central interest, however, has been a more specific question: what factors-or variables-should be considered when studying information behavior?

To answer this question, some investigators tested whether or not certain factors affected information behavior, while others contemplated which factors played a role. In contrast, very few studies were carried out without specific variables in mind, but seeking rather to uncover which factors played a role in real-life situations. We present here a multidimensional approach for such studies, and illustrate its utilization through an example: a case study of collaborative information retrieval. The study employed a naturalistic approach and focused on several dimensions simultaneously, rather than on isolated factors or variables. It pointed to a variety of factors that influenced the information behavior of the users involved. While the results of this single case cannot be automatically generalized to other contexts, the study demonstrated that these factors belong to various dimensions. Moreover, these dimensions interacted with one another. Therefore, ignoring any one of them when analyzing human-information interactions would prevent investigators from fully understanding the phenomenon under examination. The analysis of this particular case also 
revealed some of the complexities inherent in Collaborative Information Retrieval (CIR).

\section{Approaches to the Study of Human-Information Interaction}

Most research in human-information behavior has concentrated on a single dimension-either the psychological or the social-although a few researchers have considered these two dimensions together in a single study. The psychological approach focuses fundamentally upon attributes of the individual and examines psychological motivations for information behavior that carry across contexts or are independent of context (e.g., Choo, Detlor, \& Turnbull 2000; Vakkari, 2003; Yerbury \& Parker, 1998). The social approach studies the effects of the social context on information behavior, regardless of an individual's psychological attributes (e.g., Chatman, 2000; Talja, Keso, \& Pietilainen, 1999; Williamson, 1998).

\section{The Psychological Approach}

Addressing issues pertinent to the variables relevant to research in human-information behavior, the Special Interest Group on Information Needs, Seeking and Use (SIG/ USE) of the American Society for Information Science \& Technology, held a one-day symposium to address two major questions: Which variables do we need to study, and how can we measure the variables of interest to us. Working groups collected variables into an extensive list (SIG/USE, 2003). Focusing on searching behavior, most of the variables echoed the psychological approach. In addition, psychological variables were expressed in great detail and on a measurable level (e.g., level of understanding of a database structure, cognitive style, number of errors), while variables from other dimensions were expressed on a general plane (e.g., context, cultural background, social networks). This list reflects the prevailing approach among researchers in information behavior, that is, the psychological, focusing primarily on cognitive factors and to a much lesser degree on others, such as affective and perceptual factors. While a large number of studies investigated psychological variables, the field is not prepared as yet to express variables from other dimensions on a specific, measurable level.

The primary motivation for this quest for variables is the desire to predict information behavior. The argument is that once a host of relevant variables is identified, one can carry out studies to examine the effect of each variable on information behavior. After these effects are established, researchers-as well as providers of information systems and services-would be able to predict how a person with certain psychological characteristics would behave when interacting with information.

The psychological approach focuses primarily on the study of psychological states and processes in relation to information behavior. Central to this approach is the concept of information need (Fidel, 2000; Hjorland, 2003).
Like the concept of information itself, it is challenging to define, and several cognitive models were created to arrive at its meaning. Taylor (1968) made the first systematic attempt to uncover the complexity involved when he established a model describing the stages of the development of an information need. Approximations to the concept of information need were proposed by Belkin (1980) in the Anomalous State of Knowledge (ASK) model, and by Dervin (1992) who defined a gap during sense-making. Later studies employed these approaches to examine information behavior at various cognitive states, such as stages in solving a problem (Bruce, 1994; Kuhlthau, 1991), the level of familiarity with a topic (Pennanen \& Vakkari, 2002), the level of task complexity (Bystrom \& Jarvelin, 1995; Vakkari, 1999), and along individual cognitive attributes, such as approaches to studying (Ford, Miller, \& Moss, 2003).

It is not surprising that cognitive states and processes gained center stage in information behavior research. After all, human-information interaction is a cognitive process, not a physical or social one. Yet, most creators of conceptual frameworks and models in the psychological tradition would probably agree that additional factors that are not psychological—such as the physical environment, cultural background, and goals of a search-affect information behavior. Dervin (1992) emphasized that information behavior was also determined by situational elements in the environment in which a person operated. Similarly, Brown (1991) pointed to a range of barriers to information seekers, such as organizational structure and the physical environment. Recognizing the existence of other dimensions, however, does not contradict the psychological approach. Although not explicitly stated, the implicit assumption is that psychological states and processes determine the course of an information-behavior event, but these states and processes can be affected by factors from other dimensions, such as the social and the environmental. The role of the psychological approach is not to investigate what affects cognition, but to focus on how cognition affects information behavior.

\section{The Social Approach}

In contrast to the psychological approach, the social approach focuses primarily on the study of social, organizational, and political states and processes as impetus for information behavior. Pioneered and led by Elfreda Chatman in the early 1980s, this approach examines the effect social factors have on information behavior (Chatman, 2000). It does not consider the concept of information need central to the understanding of information behavior. Instead, it assumes that the study of information behavior cannot be considered in terms of isolated individuals, or outside a specific context, but should rather focus on the social context and conditions, interaction, and discourse through which human-information interaction occurs. This approach views the human as a person who lives and acts in 
a certain context, rather than a user of information systems and services. ${ }^{1}$

Most studies that adhered to this approach employed theories and frameworks from the social sciences. Chatman (2000) used diffusion theory, alienation theory, gratification theory, and social network theory to develop her own theories of information poverty, life in the round, and normative behavior. Other theories that contributed to this research were social capital theory and ecological theory, as well as ethnographic, social construction, and sociolinguistics approaches. Researchers also studied various communities such as female janitors in a large university, elderly users of a foot clinic, the working poor, a university research group, and feminist booksellers (Pettigrew, Fidel, \& Bruce, 2001).

Because the social approach assigns prime importance to the social context, results of studies cannot be generalized across contexts. Information behavior found to be typical for the working poor, for example, would probably not be observed among members of a university research group. Moreover, that of female janitors in a large university may be different from that of the same group in a large corporation because the work places are different. As a result, research with the social approach can offer very few descriptive generalizations about information behavior. It cannot produce results that will help predict, say, how people who share certain social attributes would search the Web. Instead, the outcomes of most research projects are descriptions of information behavior of a certain group. A number of studies led to the development of conceptual constructs, such as theories, models, and new concepts (e.g., Chatman, 2000; Pettigrew, 1999; Williamson, 1998). These constructs were employed and expanded upon in later research projects.

\section{Multidimensional Approaches}

Most researchers in human-information behavior have elected to conduct their work within either the psychological or the social approach. However, a growing number of researchers believe that for a thorough understanding of human-information interaction, both are necessary, and possibly other approaches as well (e.g., Leckie, Pettigrew, \& Sylvain, 1996; Pejtersen, 1984; Savolainen, 1995; Sonnenwald \& Pierce, 2000). One of the motivations behind this approach is the need to account for the complexity that exists in human-information interaction in the real world. Unlike the other approaches, which focus on one dimension and thus reduce complexity, the underlying assumption of this approach is that the better this complexity is understood and analyzed, the more relevant the outcomes of research will be to the design of information systems and services.

\footnotetext{
${ }^{1}$ Because the approach in the study reported here includes the social dimension, the term actor is used in this paper to designate the concept of user that is commonly used in the information-behavior literature.
}

Accounting for this complexity requires methods that are highly flexible, as Solomon (1999) explained when he considered the study of information seeking in context:

... the idea of information seeking in context offers encouragement to loosen the structures of terminology, research foci, methods, and assumptions about ideal behavior to discover what the role of information in people's life is. The seemingly simple addition of the notion of in context permits a joining of not only user and system views but adds the potential of grounding both understanding and the products of the information profession in work task's, life's problems, and people's strategies for coping. Through such grounded discovery, it seems that there is a better chance of creating supports that fit the tasks and problems that people regularly face. Too, such grounding may suggest a somewhat different view of how information professionals might contribute and on what information systems might focus. (p. 150)

Some researchers have attempted to uncover the dimensions that should be considered. One tactic has been to employ one's experience and suggest relevant dimensions. Allen (1997), for example, identified four dimensions that should be employed simultaneously: the cognitive, social, social-cognitive, and the organizational. Baldwin and Rice (1997) went a step further. They developed a model based on the assumption that both individual characteristics and institutional resources influence information behavior. They then tested the model through phone interviews with 100 securities analysts. They found that in this context individual characteristics had little effect on this behavior, while institutional resources played a significant role in the analysts' information activities.

Another tactic has been to uncover these dimensions through field studies. Solomon (1999), for instance, observed and analyzed information behavior in three different contexts. He created an information mosaic for each context that represented patterns of action. When he compared these mosaics he found that common to all were the factors: action preference; way of thinking (cognitive); knowledge about task, problem, etc.; and response to the actions of others (affective). While these attributes are of the actors, he explained some of the differences among the mosaics by the dissimilarities in the constraints each context presented.

A different tactic to study the complexity involved in human-information interaction has been to employ a multidimensional conceptual framework. Such a framework can guide an investigation by pointing to elements that could be explored and by providing a conceptual construct through which findings in a particular context can be related to those in other contexts. Because of our limited understanding of all the facets of information behavior, frameworks that have been developed through field studies have proven most promising. One such framework-that incorporates cognitive, social and system perspectives-was developed by Sonnenwald (1999). She explained that the framework had evolved through field studies of different groups and the use 
of theories and research traditions form various disciplines such as communication, sociology, and psychology. Defining "information horizon" as the space in which actors can act, the framework focuses on contexts and situations that create evolving information horizons that map the location of different information sources within it. Sonnenwald and her colleagues also used this framework to guide their study of the information seeking behavior of lower socio-economic students (Sonnenwald et al., 2001).

In the same way, Lamb and Kling (2003) used a contextaware institutionalist approach to develop the concept of a social actor through a field study on the use of online databases. Their framework consists of four dimensions (p. 213): organizational and professional relationships that connect an organization member to various networks (Affiliation); stabilized, regulated and/or institutionalized practices that circumscribe organizational actions (Environment); information, resources, and media of exchange that organization members mobilize as they engage with members of affiliated organizations (Interactions); and avowed presentations of the self and ascribed profiles of organization members as individual and collective entities (Identities). They used this framework to guide their studies on the use of intranets in American firms, and on the role of information and communication technologies among academic and industry scientists.

Another framework that has been used to study humaninformation interaction is Cognitive Work Analysis (Vicente, 1999). While it was developed through field studies of interactions in process control, the framework has been guiding studies in information seeking as well. Pejtersen (1984), for example, adopted it to study fiction retrieval in public libraries. Her study informed the design and development of BookHouse, a retrieval system for fiction. Similarly, Fidel and her colleagues (1999) used the framework to analyze data collected through observation and thinkaloud protocols of high school students who performed Web searches to complete homework assignments.

Generally, studies that employ a multidimensional approach usually focus on a specific group of people, in a certain context, often performing a particular task. The case study reported here was no exception. Using this case study, we introduce in this paper the concept of Cognitive Work Analysis and illustrate how employing it can reveal not only the various factors involved in an information-behavior phenomenon, but also the interdependencies among these factors.

In this paper, we: (a) present the multidimensional conceptual framework we employed in the study, (b) share the knowledge gained from the case about motives and challenges to CIR, and (b) demonstrate the role and interdependence of the psychological, organizational, and social dimensions in human-information interaction. To show how we integrated multiple dimensions in this project, we first present the conceptual framework that guided our work.

\section{The Conceptual Framework: Cognitive Work Analysis}

Cognitive Work Analysis (Vicente, 1999) is a workcentered conceptual framework developed by Rasmussen, Pejtersen \& Goodstein (1994), and its purpose is to analyze cognitive work. The framework's theoretical roots are in General Systems Thinking, Adaptive Control Systems, and Gibson's Ecological Psychology, and is the result of the generalization of experiences from field studies which led to the design of support systems for a variety of modern work domains, such as process plants, manufacturing, hospitals, and libraries.

Focusing on information behavior on the job, CognitiveWork Analysis views human-information interaction in the context of human-work activities. One considers the work activities, their organizational relationships, and the constraints of the work place that impact the activities. One also takes into account the actors' cognitive and social activities and the values that guide them as well as their priorities and personal preferences when they perform a task on the job. This interaction between work and human actors is mediated through the task an actor performs, the decisions she makes, and the strategies she uses to solve problems. Because actors often collaborate with one another to do their work in the modern work place, collaboration among actors is an important aspect of this human-work interaction.

Unlike the psychological and the social approaches, Cognitive Work Analysis focuses simultaneously on the task actors perform, the environment in which it is carried out, and the perceptual, cognitive, and ergonomic attributes of the people who typically do the task. A graphic presentation of the framework is given in Figure 1. In this presentation each set of attributes mentioned above is designated with a circle and is considered a dimension for analysis. Thus, each dimension is a host of attributes, factors, or variablesdepending on the purpose and method of a study. Table 1 provides examples of questions that would be asked when analyzing each dimension.

The assumption that human actions are goal-driven has been an important element in the approach that guided the development of the Cognitive Work Analysis framework. This implies that human-information interaction in any context is not the result of random or idiosyncratic forces. Rather, it is steered by some goals, whether explicit or implicit, personal or organizational, stable or situational. Once we accept this assumption, it is clear that merely describing human-information interaction is not enough to fully understand this interaction. Knowledge of the reasons and motivation that lead actors to interact in a certain way is necessary as well.

This approach is not common in research about humaninformation behavior. Most studies that have addressed elements of this behavior have been primarily descriptive, if in different ways. Numerous research projects have reported on the information behavior of a certain group of actors: how they seek information, where they search, how they 


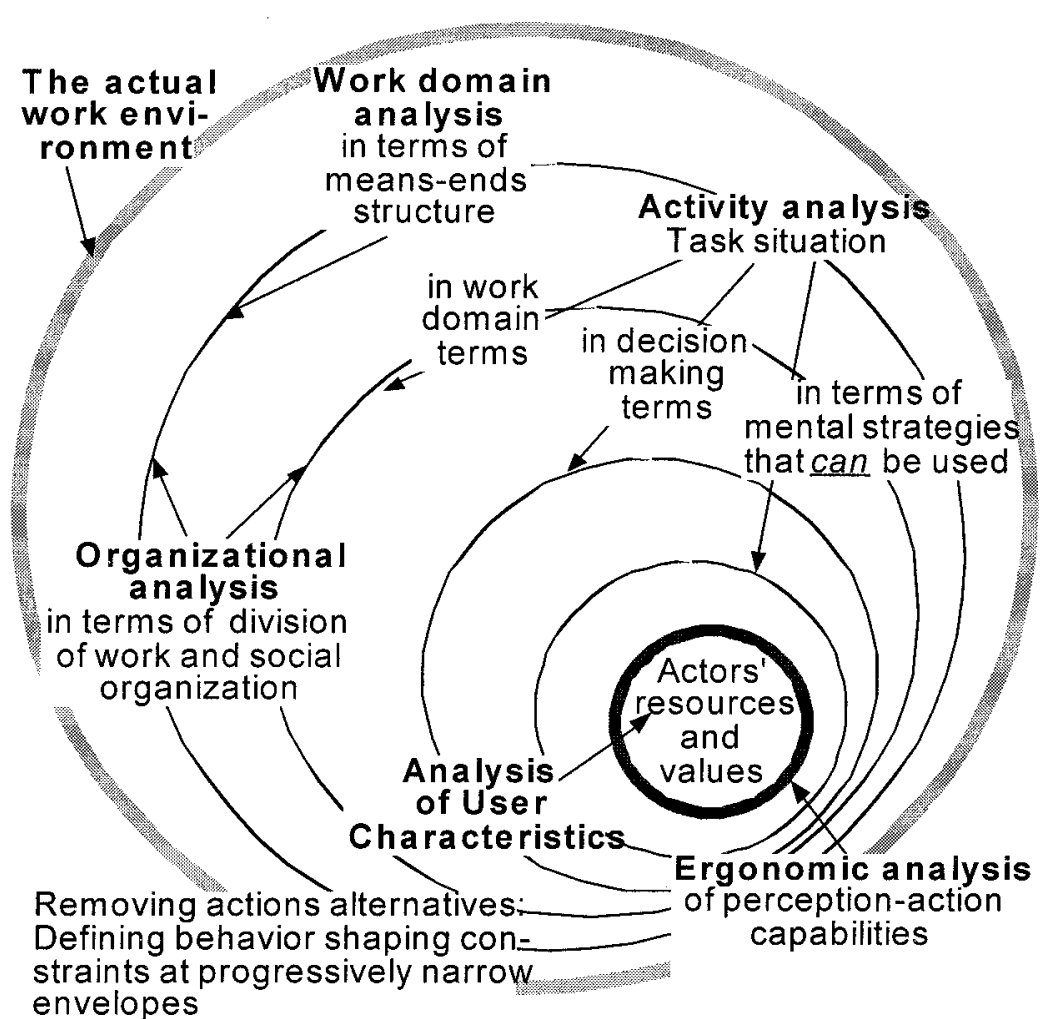

FIG. 1. Cognitive Work Analysis.

search the Web, when they are satisfied with retrieval, and so on. Other investigations have looked for correlations between variables that may imply causal relationships, such as that between gender and the number of mistakes in Web searching. Correlation by itself, however, does not imply causality, and therefore cannot explain results, just present them. At times, investigators have considered reasons for a certain behavior to explain the findings of their analyses. One may suggest, for instance, that boys made fewer mistakes in Web searching than girls because boys are more likely to be trained in using technology from an early age than girls. These explanations, however, are usually mere

TABLE 1. The dimensions of the Cognitive Work Analysis and examples of questions to ask when analyzing each dimension.

\begin{tabular}{|c|c|}
\hline Dimension & Examples of questions to ask in analysis \\
\hline Environment & What elements outside the organization affect it? \\
\hline Work domain & $\begin{array}{l}\text { What are the goals of the work domain? The constraints? The priorities? The functions? } \\
\text { What physical processes take place? What tools are employed? }\end{array}$ \\
\hline Organizational analysis & $\begin{array}{l}\text { How is work divided among teams? What criteria are used? What is the nature of the } \\
\text { organization, hierarchical, democratic, chaotic? What are the organizational values? }\end{array}$ \\
\hline Task analysis in work domain terms & $\begin{array}{l}\text { What is the task (e.g., design of navigation functionality)? What are the goals of the task } \\
\text { that generated an information problem? Constraints? The functions involved? The tools } \\
\text { used? }\end{array}$ \\
\hline Task analysis in decision-making terms & $\begin{array}{l}\text { What decisions are made (e.g., what model to select for the navigation)? What } \\
\text { information is required? What sources are useful? }\end{array}$ \\
\hline Task analysis in terms of strategies that can be used & $\begin{array}{l}\text { What strategies are possible (e.g., browsing, the analytical strategy)? What strategies does } \\
\text { the actor prefer? What type of information is needed? What information sources does } \\
\text { the actor prefer? }\end{array}$ \\
\hline Actor's resources and values & $\begin{array}{l}\text { What is the formal training of the actor? Area of expertise? Experience with the subject } \\
\text { domain and the work domain? Personal priorities? Personal values? }\end{array}$ \\
\hline
\end{tabular}


speculations and are not based on a systematic analysis of evidence. Their purpose is to provide possible explanations for the observed data, not to improve our understanding of the motivation for certain information behaviors.

Cognitive Work Analysis has several other distinct attributes that are useful for the study of human-information interaction and for the design of information systems and services. Most importantly, it provides for a holistic approach that makes it possible to account for several dimensions simultaneously. In addition, the framework facilitates an in-depth examination of the various dimensions of a context. A study of a particular context is, therefore, an interdisciplinary examination with the purpose of understanding the interaction between people and information in the work context. These two attributes make the framework a powerful guide for the evaluation and design of information systems and services for the context under investigation because in reality all facets-personal, social, technological, and organizational-play a role simultaneously and interdependently. Finally, while the framework is based on a set of theories, it provides a structure for the analysis of human-information interaction, rather than subscribing to specific theories or models. One can employ a wide variety of conceptual constructs or tools that may be deemed helpful for the analysis of a specific situation. This flexibility turns the focus of an investigation to the phenomenon under study, rather than to the testing and verification of models and theories.

While the Cognitive Work Analysis allows for flexibility, it has also built-in mechanisms to carry out rigorous and systematic research. In addition to the dimensions for analysis, it provides several templates to support both analysis and modeling. The study reported here used one of these templates for analysis: the Decision Ladder. Briefly, the Decision Ladder describes an ideal, purely rational decision-making process. It consists of three phases: situation analysis, evaluation, and planning. In the first phase actors analyze the situation to understand the problems that need to be resolved and the circumstances involved. The second phase involves an evaluation of the options, considering the possibilities and the consequences of each option. After a decision is selected and made, the third phase begins when actors plan how to carry out the decision.

When analyzing data collected in a study, the Decision Ladder acts as a template to which data is mapped, rather than as a structure for constructing a normative model about decision-making. It is not assumed that actors should follow the phases consecutively, but the template is used to map the decision process. In our analysis, we found that the actors in this case rarely followed this process sequentially, and quite often did not complete a phase before they moved to another one. At the same time, mapping the case to the template made it possible to understand at what phase of the decision-making the actors were in a given time, what information they needed in the various instances of information processing, how they collaboratively retrieved it, what helped their information retrieval, and what hindered it.

\section{A Case of Collaborative Information Retrieval}

This case study was part of a large-scale study to explore the manifestations of collaborative information retrieval (CIR) (Fidel et al., 2001). To achieve the goal of the large-scale study, the project investigated three teams: a design team in Microsoft, another in Boeing, and a customer-service team in Boeing (Bruce et al., 2003, Poltrock et al., 2003). The case reported here is that of a decisionmaking process by a member of the Microsoft design team.

Our understanding of the concept of CIR evolved as the project progressed. One aspect is the notion of collaboration. There are various situations in which people look for information together. A librarian may help a user in the library, for instance, or a customer-service engineer may contact a designer to help her look for information. Are these instances of CIR? According to our understanding, information retrieval is collaborative only when the actors involved are colleagues; they are engaged in the same work processes. Thus, if two librarians, for example, look for information together, they are collaborating in information retrieval. Similarly, if a customer-service engineer receives help in finding information from team-mates, they are all collaborating.

In addition, previous field studies found that in some work situations CIR is interwoven with work and cannot be studied separately (e.g., Paepcke, 1996; Reddy \& Dourish, 2002). This proved to be the case in this study as well. Therefore, instead of limiting the investigation to the act of retrieving information, the research team construed the concept information retrieval to include all activities that were taken by actors to resolve an information problem. At the same time, we considered direct communications among those involved in solving a problem-which often involved information exchange-as information sharing, rather than retrieval. For such an exchange to qualify as retrieval, it required the actors to acquire information they did not already have. Thus, the team identified CIR as any event in which actors who participated in the same work process collaborated to resolve an information problem that required them to use resources external to their own knowledge.

An example of a CIR situation is the case study described here. In this case, one actor had to make a decision for which he needed some information. He invited two colleagues to help him seek this information, and the three of them worked on resolving the information problem together. One of the colleagues was a member of the actor's formal team, and the other only joined the team later but was already highly familiar with the team's project and work.

\section{The Method}

Being a naturalistic field study, interviews and observation were the major techniques for data collection throughout the project. To this end, the research team:

1. Interviewed the team manager.

2. Observed interactions between team members at meetings. 
3. Interviewed individual team members.

4. Observed team members at work.

5. Reviewed communication network diagrams that were constructed based on team members' reports about the frequencies of their communications with each other and with people in related organizations.

6. Monitored e-mail threads.

7. Examined documents related to the team and the project.

The questions in all the interviews followed the dimensions in the Cognitive Work Analysis. Each dimension generated a list of questions that were relevant to the particular situation, to the actor's role in the team and in the team's task, and to the factors that were included in the dimension. Table 1 provides some examples of such questions. The interviews were conducted by the researchers at the actors' offices and followed an interview schedule of open-ended questions. During most of the interviews the mood was relaxed and all involved were engaged in conversations as well.

The interviews and think-aloud protocols from observations were audio-taped and transcribed. The research team also used the Cognitive Work Analysis framework to analyze the data. The framework provided a template for developing detailed descriptions of the work tasks, decisions, communication and collaboration, information needs, and the strategies, tactics, and heuristics that team members used for obtaining information. It also guided an analysis of the organizational goals, structure, and culture of the workplace. The researchers prepared a report on these observations that was shown to the team manager and some team members for comment, correction, and validation.

Here we analyze a single case in which a team member had to make a decision about the design of the navigation functionality of the product. Data for this case were collected through observation and taping of the verbal communication between the lead design engineer, Neil, ${ }^{2}$ and his collaborating colleagues. Other sources of data were used in the analysis of this case: notes taken during the observation, interviews with Neil and others, transcripts of team meetings, and various documents relating to the design project. The transcript of the interchange during the case and the notes supported a detailed understanding of the specifics of the case. Data collected through documents, interviews, and meetings' transcripts provided background information that made it possible to place the particular case in the larger context, and to consider aspects that were not present during the interchange but were relevant to the case.

\section{The Microsoft Design Team}

The design team that participated in the study took part in the creation of the Help and Support Center (HSC) for Microsoft. The goal of the HSC project was to design a unified, useful, and usable help portal for end users of

\footnotetext{
${ }^{2}$ The names of study participants have been changed.
}

Microsoft products. In accordance with the Microsoft tradition, the division of labor within the project as a whole was based around four teams: Test, Development, Program Management, and Design. Each team was responsible for more or less clearly defined aspects of the work involved. The team we studied was the design team, responsible for both product design and visual design. The product unit manager, who was responsible for the entire HSC project, set the project vision that determined the bounds within which the team worked.

The HSC would be a Web-based portal that would provide a single unified access point for a wide variety of help information, such as help about local applications, remote help repositories, and updates. Much of the content already existed in separate systems, and the design team had very little direct control over it. Two aspects of the system were new and presented unique design challenges: (a) the portal would provide an integration of many kinds of help content and updates, and (b) the content would be dynamic. As a Web-based service, and not a shrink-wrapped software product, the HSC was different from many traditional Microsoft products. In particular, this meant that the design and development could never be considered complete, and the service would continue to evolve over time. The project was just beginning as we started our study, enabling us to observe a design team during the initial stages of developing a new Web-based product.

The benefits of the system would be to make it easier for end users (both individual consumers and information technology professionals) to find help information to solve their problems. Also, the system would provide Original Equipment Manufacturers (OEMs) with a single point of contact for providing their own help content. This would make interactions with OEMs more effective and enable them to easily add their own help content and present it to users in a unified form. The design team needed to consider how this would influence indexing and navigation, and how users would be notified of changes. In addition, the team needed to have a good understanding of the users and what types of help requests they would present to the HSC system. This information was difficult to obtain because the product was new.

The design team consisted of about 10 people who had been at Microsoft for between 4 months and 7 years. Throughout the 3-month period of observation, some people left the team and others joined. Among those who stayed from the beginning to the end of the observation period were three product designers, two visual designers, two usability engineers, and the manager. A manager led each team, but all teams involved in the product were part of a larger effort led by a unit manager. While it was the product unit manager who, along with the managers for each of the teams, set the high-level project goals, within the design team, it was the manager who was responsible for setting the main goals. She did so with a good deal of interaction among team members to set priorities and refine goals over time. 


\section{The Case of Navigation Design}

Neil, the product design lead on the project was scheduled to meet with a member of the development team to discuss navigation issues in connection with the first HSC prototype. Even though this issue was on Neil's to-do list, the issue's complexity was not clear to him until the last minute and he was, therefore, forced to prepare, as he put it, "on the fly." Although this method of working was rather common, Neil felt that he should have prepared a written specification. So, while Neil had previously considered what he needed to discuss with the developer, he was concerned that his preparation had not been thorough enough. To address this problem he decided to call in two colleagues, Evan and his assistant, Victoria, so that he could discuss the issues with them before he discussed them with the developer. At the outset, Neil was not able to contact Victoria and so he and Evan proceeded without her. Although Evan was not officially part of the HSC design team at that time, he was a designer and had been closely involved in the development of the project. Moreover, he joined the team shortly after the case reported here took place. After some discussion, and learning what Neil needed, Evan suggested calling in Lily, a usability engineer who was on the design team, and she joined them.

Neil's role was to specify to the development engineer the navigation functionality in general, and, specifically, the desired model for the forward and backward navigation. He wanted to provide a high-quality design, and needed knowledge of user behavior and user preferences. In addition, he had a limited time in which to arrive at a decision, and he had to ensure that his work was coordinated with the work of the different teams. To help him in his decision, he wanted to know what navigation model had been used in the previous version of the Help and Support software. To that end, he decided to access this program and figure out what navigation model it had used. When Evan entered his office, Neil was already in front of his computer examining that version of the software. This was the only information source used by the actors in this case of CIR. It provided information about the design logic that had been applied in the past and allowed the participants to assess the strengths and weaknesses of the decisions that had been taken in relation to the product. Neil needed this information and assessment to cement his own decision about the navigation model for the new system.

With relation to the Decision Ladder, the actors spent all their time dynamically moving between the first two phases: analysis and evaluation. A number of times they evaluated options (the second phase) without sharing their understanding of the situation (the first stage). At the end of the process, Neil made a decision and he directly went to meet the development engineer. He did not share his decision with his colleagues, however. Therefore, the third phase (planning) did not involve CIR. In fact, it was completely missing in this case.
Why did Neil invite his colleagues to collaborate with him in finding the information he needed? What challenges did they face during this collaboration?

\section{Motives and Challenges to Collaborative Information Retrieval}

Data analysis revealed that several dimensions of Cognitive Work Analysis contributed to the elements that made it beneficial for Neil to collaborate with others. Some also presented challenges for this collaboration. These dimensions were:

- The cognitive dimension (Actor's resources and values, Fig. 1.)

- The specific task and decision (Task situation)

- The nature of the information sources

- The nature of the information needed

- The organization of the team's work (Organizational analysis)

- The organizational culture (Organizational analysis)

While each dimension had its own role, contributions from each dimension affected those from others.

\section{The Cognitive Dimension}

At the time this case occurred, Neil had been employed by Microsoft for only 4 months. This fact by itself provided an important reason for him to collaborate with others, but it also made most of the other motives for collaboration more critical than they would have been for an experienced employee.

As a novice to the organization, this CIR encounter served Neil on various levels. For his immediate information retrieval task, he needed the support of more experienced actors in trying to figure out how the previous system was designed. Although none of them was familiar with the previous system, their experience with the company's products and design would accelerate the process of deciphering the systems' logic. For the design task itself, the collaboration provided him with a broader perspective with regard to the organization, so that he obtained knowledge about related work and relevant actors. This allowed him to add to the stock of his knowledge and thereby develop and refine what he planned to discuss with the developer.

Equally important, however, was what he learned about the constraints that impinged on the task. Although Neil was inexperienced in the Microsoft context, he had a good deal of professional experience relevant to the task and had already prepared himself for the meeting with the development engineer. It is not, therefore, for fear of a lack of things to discuss that he sought further information. The point was, rather, that he needed to know precisely what was realistically achievable and, from this baseline, match his ambitions as a designer with the ambitions and interests of the development team. This advantage of the collaboration was 
highlighted in the data we collected. A large part of the verbal communication related to the consideration of design constraints. For his future work in the organization, collaboration with experienced employees helped him to find new information sources and to get a better understanding about how the work place is organized.

Further, Neil selected partners for the CIR event who would complement his expertise. While he was an experienced designer, he was not particularly familiar with Web technology. Having Evan by his side while he retrieved information from the display of the previous system was beneficial because Evan was highly experienced in Web design. Indeed, it was Evan who took the lead in navigating through the system and uncovering the information Neil needed because he was aware of the logic by which the previous system operated. In addition, Neil's knowledge about users and their information behavior was limited. One of the requirements for the design stated that the product would provide help experience that would be helpful to users. Therefore, adding Lily, a usability engineer, to his collaborating team helped him to examine the information from a users' perspective.

In addition to help in the cognitive processes involved in information retrieval, Neil acquired tacit knowledge from his collaborators as they contributed their expertise during the CIR process. This knowledge helped him not only to find the information he needed for the decision he wanted to make, but also to enhance his understanding of the way the company and its products worked. At the same time, CIR presented cognitive challenges to him as well.

Cognitive overload was the main drawback of CIR in this instance because the collaboration added cognitive processes to Neil's task of information retrieval. Most obvious was the complexity of the process because information was being retrieved simultaneously by different actors. It was not uncommon for the three of them to look at a screen and each retrieve a different piece of information. Neil faced the challenge of processing all these pieces of information and memorizing them as well. In addition, while Neil's aim was to answer specific questions about the navigation model of the previous system, the discussion among the collaborators took the character of a brainstorming session. Even though both Evan and Lily joined Neil to look for the information he needed, they had their own interests, and their stakes in the process were different from his. At times, this caused a shift in the collective focus, which Neil had to negotiate and redirect to the problem at hand.

The fact that Neil needed to explain the problem and the decision to be made, with all of its intricacies, to both Evan and Lily, added to his cognitive load. In fact, Neil himself recognized the potential for cognitive overload. When Evan suggested that they invite Lily to join them, Neil refused at first, because he did not want to disrupt the momentum that they had achieved in their discussion. Time was limited, and bringing an additional participant to the collaboration would require a shift in the discussion. Eventually, Evan persuaded Neil that Lily, by virtue of being a usability engineer who was familiar with the issues they had discussed, could join them without extensive briefing. He also estimated that bringing her into the discussion would be offset by what she could contribute to CIR and to their knowledge about users. Evan's predictions were correct. Even though adding a participant to the collaboration increased Neil's cognitive load, Lily was able to contribute new ideas and retrieve additional information that was relevant to Neil's decision.

This incident illustrates another cognitive task that is unique to CIR: the decision that Neil had to make about whom to invite to the collaboration. While at times the partners in CIR would cluster naturally by virtue of the task performed or the decisions made, in this case, Neil was the one responsible for making a decision, and it was not obvious who would be the best collaborators. This challenge was particularly critical in Neil's case because he was new to Microsoft with a limited personal network. Were he connected to a larger number of experts within the organization, this decision would have been better informed, and possibly easier to make. The position as a newcomer also magnified the other challenges. As the actor with the least expertise on the CIR team, at times Neil had difficulties managing the process and keeping everyone on track, even though he initiated the CIR event.

\section{The Specific Task and Decision}

The nature of the task in which Neil was involved (design) and that of the decision he wanted to make (which model to use for backward and forward navigation) called for CIR for several reasons. Specific attributes of the task at hand added motivation.

The HSC team was at the beginning of the design process. Neil, for instance, was still contemplating the navigation functionality for the first prototype. At this early stage only a few constraints for the design were set, and the situation was new to all team members. Several of them made special efforts to elicit design specifications from other employees with partial success. As a result, an important and frequent activity in CIR events was the search for possible constraints that could guide their work. Being a novice, Neil had an open design space in front of him, and since there were no detailed specifications for the part of the product for which he was responsible, it was his job to formulate specifications for the new product. Therefore, he needed to call a CIR meeting to obtain information from people with more experience with the company's products, the policies involved in product development, and the significance of that experience to the task at hand. This situation presented a challenge to CIR as well.

Evan, for example, took up issues concerned with visual design on a number of occasions and on each occasion Neil was quick to deflect attention away from this area. This was an important challenge for the CIR activity since everything was potentially open for discussion at the stage where specifications for the first prototype were being determined. However, Neil was only concerned with the navigation 
design, primarily because this was his designated area of responsibility within the team and also because he felt that changes to the navigation design were more difficult to implement and should therefore be given greater priority.

Further, because the project was in its early stages, Neil was preparing to participate in one of the first encounters between the Design and the Development teams. Since little information had been exchanged between these teams, and thus little was known about the respective interests and agendas of the different groups, Neil would benefit from interaction with other actors who were involved in the design. The fact that the responsible party, Neil, was a novice within the organization exacerbated the requirement for CIR. This situation also created a challenge. Because the encounter was in the early stages of the project, issues under discussion were broad in their scope, affecting the whole navigation experience in the product. Clearly, Neil was more acutely aware of this than the others involved in this instance of CIR, and throughout the process he tried continuously to steer the discussion away from the consideration of finer details in the design.

Not only was the HSC design team developing a new product, they were working on designing an entirely new concept. With new software design being a highly dynamic process, this required a close collaboration among the team members. In the navigation model case, information retrieval was an integral part of the creation of the new design concept. And because design activities were carried out collaboratively, so was information seeking. Neil and his collaborators assessed the information they retrieved, used it to generate new ideas, and to reflect on the new design.

Having to develop a new concept, however, also had its drawbacks in relation to CIR. Working on design is an innovative process. As a result, actors are required to be creative. They tend, therefore, to freely associate and elaborate ideas and their implications, which are not always relevant to the immediate problem. The case reported here was no different. Both Evan and Lily were highly active in bringing up ideas and contributing suggestions, and Neil was faced with a constant stream of diverse ideas. As a result, he did not always immediately understand the information they retrieved. Only later in the discussion did their contributions become clear to him.

The nature of the information source. The information source in this case was an artifact: the previous system. Throughout the CIR event, the participants huddled around the computer in Neil's office and interacted with the system. Their goal was to figure out the structure and the design principles behind it, which were not readily available. Therefore, the task was not easy and required speculations and hunches about where to retrieve needed pieces of information. Because the structure of this information source required interpretation, it was to Neil's benefit to have collaborators who could contribute their own knowledge and expertise. Their contribution was particularly meaning- ful because of Neil's inexperience with the system and the company.

It was Neil's idea to examine the previous system to find the information he needed about models for navigation. This had the immediate advantage of helping him familiarize himself with the relevant technological framework within the organization. It was also a limiting factor, however, because the artifact itself could not provide ideas for a new concept. Having discussion and interaction with colleagues during the search for information helped Neil to keep a fresh perspective and not get bogged down with the design details of the previous system.

The nature of the information needed. Possibly the strongest motivation for CIR in this case was the fact that most of the information needed for the design was not documented. Like other team members, therefore, Neil could not rely solely on his own knowledge about information sources when he looked for information. It required discussion and exchange of ideas. This was particularly the case for Neil who was new to the organization and was not familiar with other people and the information they had.

Additional facts motivated Neil to seek collaborators. The information they retrieved from the previous system lent itself to various interpretations, and required various kinds of expertise to interpret. Calling on an expert in Web technology and another in usability, Neil ensured that the information they retrieved collaboratively would be interpreted from the relevant aspects, and by experts. Moreover, the information might have various implications to the problem at hand. Having experts by his side who had experience with the organization, Neil could gain a broader coverage of these implications than if he were retrieving the information by himself.

\section{The Organization of the Team's Work}

The way the work was organized within the HSC team also motivated Neil to initiate a CIR event. In general, team members had to define their own tasks within their area of responsibility. This presented Neil with several complexities, all of which were eased with CIR.

To define his task, Neil had to identify his degrees of freedom. He did so by looking for constraints on his task. The interaction with the retrieved information and with colleagues helped him to ascertain these constraints, as explained earlier. In addition, having the freedom to modify his task brought additional responsibilities. Neil did not act as an individual designer but as a representative of the HSC team. Therefore, his meeting with the development engineer would have a great impact on the work of the whole team. It would affect the design of the product, which is a vital issue for the team, and it would be one of the first building blocks in the reiterations the team would have with the Development group. Recognizing his responsibility, Neil decided to prepare as thoroughly as possible for the meet- 
ing. Involving others in the search for information helped him to reduce the possibility that some information would be overlooked. This way, his decision would be based on the best information available. In addition, while the declared purpose of the CIR gathering in his office was to figure out the navigation model of the previous system, Neil received much informal feedback to his ideas from Evan and Lily. Even though the team did not review his design proposal about the navigation functionality, the opinions of his CIR partners helped him to arrive at his decision, knowing that various aspects had been considered.

\section{The Organizational Culture}

The work procedures in Microsoft and the company's culture and tradition were at the root of Neil's information behavior. Like all employees in similar organizations, he worked in the "Microsoft way." It is beyond the scope of this paper to provide an in-depth description of how the company manages people and develops products. This has already been depicted in various books and articles (e.g., Cusumano \& Selby, 1998). However, two examples of the "Microsoft way" are presented here.

One effect of the company way on Neil's information behavior is the fluidity in the definition of task. Both the interview data obtained in this project and the literature about Microsoft indicated that while individual actors have full responsibility for their tasks, the boundaries of the task responsibility are not always clear to either the team or to the actors themselves. Neil captured this issue when he explained:

People don't always know what they're meant to be doing. They kind of step on people's feet and duplicate work sometimes. And even beyond that, it's not always clear what part of the design, even within navigation, what we're responsible for within the team. How do you divide the screen up? I'm responsible for this chunk, you're responsible for that chunk. How does that get defined? Things cross over each other. I guess one of the challenges of the job is to figure out what your task is and define it yourself ... I think figuring out the task is part of the task. It's a metatask.

While task allocation is well organized, any given task may represent numerous possible solutions. Moreover, the boundaries of the task and its solutions are dynamic and may change as a result of developments in other units in the organization. The CIR process helped Neil to understand what possible solutions are most appropriate and how his task related to other aspects of the design. It helped him understand what can legitimately be done, given the organizational constraints and the existing technological frameworks.

Another example is the lack of a formal structure in the organization that can guide actors in identifying people in the organization who might have the information they need.
As a result, most staff in the company rely on their own personal network. Neil, however, had not established one yet, but it had been one of his priorities since he joined the organization. He explained:

You try to identify people who have certain knowledge, who've been here for a while; you try to talk to them. A lot of networking, called working the organization. You'll speak to somebody and they'll send you someone else's name and you'll go and speak to them and they'll mention someone else's name and so forth. Eventually a group of people who are the players in this will emerge and you talk to them mostly.

The CIR event aided Neil in his endeavor to develop his personal network. Through the interaction with colleagues with more experience in the organization he gained more insight about possible contacts and people to whom he could turn for information.

\section{Discussion}

This case study contributes to research in human-information interaction by illustrating the importance of a multidimensional approach and the effectiveness of the Cognitive Work Analysis framework as such an approach. In addition, the study provides new insight into our understanding of collaborative information behavior (CIR).

\section{Multiple Dimensions}

The basic assumption in Cognitive Work Analysis, that humans are goal-driven, was central to this CIR study. It was natural, therefore, that one of the questions the project addressed was what motivates actors to turn to CIR? The analysis of the case of navigation design illustrates that it is feasible to answer this question comprehensively. It is possible, of course, the answer is not complete because Neil had additional reasons for collaborating with colleagues that we did not uncover. Still, the elements of CIR motivation that the project discovered display the interplay among the cognitive and social dimensions and offer a better understanding of the phenomenon.

The dimensions of the Cognitive Work Analysis framework and the guidance provided by the Decision Ladder made it possible to consider various factors when looking at one issue. An analysis of the task situation, for example, brought to light the nature of the task in which the design team was involved (e.g., dynamic, new, evolving, at an early stage). This, in turn, highlighted the contributions of the task's characteristics to the motivation to engage in CIR. These motivations were further strengthened by the actors' resources and values (e.g., insufficient knowledge about the organization), and by organizational factors that have been uncovered through the organizational analysis (e.g., flow of information through personal networks). 
No factor in isolation could have explained why Neil elected to convene a CIR session, rather than look for the information he needed by himself. Clearly, the fact that he was new to the organization provided a strong incentive for him to consult with experienced colleagues. It is not clear, however, if he would have been in the same situation were the task he performed stable, routine, repetitive, and in its last stage. Similarly, it is possible that Neil would have looked for information by himself if the information he needed were documented, if the decision he had to make would not have affected the work of the whole team, or if he had a clear notion about the boundaries of his task. No factor seemed to be more pertinent than the others. All these factors worked together to motivate Neil to turn to CIR. Because they represent different dimensions, it is clear that various dimensions had to be explored-including the cognitive and the social— to understand the incentives for a CIR event.

A study of CIR that employed the Cognitive Work Analysis framework in another context also examined the effects of various dimensions. Hertzum et al. (2002) analyzed three European film archives to assess the potential of designing a collaboratory that supports and enhances the work in the archives and the collaboration among them. In one archive, for example, they found that the archivists often collaborated informally and on an ad hoc basis when they retrieved information for users. Their collaboration was motivated by factors from various dimensions. On the actors' dimension, the archivists all agreed that they needed to collaborate because their different backgrounds and interests complemented one another. The task itself contributed to the need for this collaboration because even a seemingly simple request for a film on the basis of its title, director, and production year may turn out to be rather complex and may require different types of expertise. This thorough approach to the retrieval of information for users was reinforced by attributes from the organizational dimension: the management of the organisation placed highest priority on commitment to the public and to the quality of user services. In addition, the self-organizing nature of the work groups in the archive in general facilitated the creation of ad hoc teams for CIR.

The analysis of the data in this case also showed that often it is difficult to clearly distinguish among the dimensions involved because they are intertwined. In analyzing Neil's search for design constraints, for instance, it was difficult to determine what role was played by the nature of the task and what by his inexperience. Further, a factor in one dimension may depend on a factor from another. For example, Neil's limited knowledge of the organization (a cognitive factor) motivated him to employ the CIR event to gain confidence in his decision when representing the team as a whole (an organizational factor). Likewise, the nature of the task (design) and the stage in the process (the beginning stage of the product with very few constraints and an open design space) brought cognitive overload because Neil had to keep the CIR event on track when his partners pulled the conversation in alternative directions.

Such interdependencies suggest that focusing on a single dimension may not only provide a partial understanding, but might also be misleading. Analyzing the data collected in the case study only from a cognitive point of view, for instance, one would observe that, repeatedly, Neil had to bring the others back on track. It would be easy to conclude that this was a typical challenge of CIR. Our analysis showed, however, that this tendency was reinforced by the nature of the task. Another factor was the fact that this was Neil's decision to make, while the others had other interests as well, and tended to derail the conversation. Thus, a CIR team, in which each actor has the same stake in the information problem, and that is dealing with a well-defined situation may not encounter the same cognitive overload.

Moreover, the analysis here illustrates that when faced with the complexity of real-life situations, it is effective to employ a framework, such as Cognitive Work Analysis, as a guide to unravel the contributions of the various dimensions. While most field studies witness this complexity, it is often difficult to uncover patterns, or even fully understand the phenomenon under study. Cognitive Work Analysis provides not only the dimensions a researcher should consider, but also templates - such as the Decision Ladderthat aid the researcher in the analysis of complex and dynamic situations. Such guided analyses facilitate a systematic understanding of circumstances that seem chaotic and thus difficult to comprehend.

The various dimensions that contributed to the CIR motivation and the rich relationships among them indicate that a one-dimensional approach limits both the researcher and the strength of a study's results. While explicit awareness of the dimensions involved assures investigators that their analysis is comprehensive, only an appreciation of how factors from various dimensions interact can support an in-depth understanding of the phenomenon under study.

\section{Contributions to the Study of CIR}

When a work team is engaged in a CIR activity, they operate within the organizational framework in which they work. Organizational communications research has produced a considerable literature on team and group communications across organizational boundaries, especially in the context of work groups. While many observed information behavior in team communication, their purpose has usually been to uncover general patterns in this behavior, rather than an in-depth understanding of a particular type of group. Ancona and Caldwell (1992), for example, examined the nature of work relationships, vertical and horizontal, in which information flow occurs. Others examined the roles that group members play in relation to information. Some of these studies focused on the difference between actors outside the group and those inside it, and the complexity involved in determining where some actors belong (e.g., Algon, 1996; Paepcke, 1996), and others created typologies 
of actors and their specific roles (e.g., Ancona \& Caldwell, 1988; Sonnenwald \& Lievrouw, 1996). In an early review of the literature, Ancona and Caldwell (1992) observed that, at that time, no research addressed the content or purpose of these information communications. While Paepcke (1996) addressed this aspect when he examined the difference between the type of information that is being transferred to a group from outside, and that the members of a group share, Guinan, Cooprider, and Faraj (1998) concluded that "Little research has attempted to discuss and operationalize the specific activities that individuals perform when exhibiting these [information] roles."

The CIR case reported here offers a unique contribution to this literature. It focuses on a design task at a stage that requires much information-the design specification stage (Govindarej, Pejtersen, \& Carstensen, 1997; Guinan, Cooprider \& Faraj, 1998; Sonnenwald \& Lievrouw, 1996) — and it provides a detailed and in-depth understanding of the interaction dynamics of collaborative information behaviors during problem-solving and decision-making.

Although the case study analyzed a single CIR encounter, it enhances our general understanding of this phenomenon. Based on the data collected in this study, and particularly in this case, we can state that certain attributes of human-information interaction may motivate actors to participate in CIR. Similarly, we can begin to understand the challenges to this activity.

This case illustrated that actors may be motivated to engage in CIR when:

On the Actors' dimension:

- They are novices, new in the organization, or when they are in an unfamiliar situation.

- They are looking for some informal feedback to their ideas, and opinions about the decision they are about to make, which could be elicited through the CIR process.

- They need to access tacit knowledge.

\section{On the Task Situation dimension:}

- They want to get access to additional and diverse sources.

- It is not possible to follow a normative procedure and they are pressed for time and need to make a decision swiftly.

- The decision that needs to be made requires thorough preparation, making sure that nothing is being overlooked.

- The structure of the information source is not easy to understand and requires analysis and speculation.

- The task requires a close collaboration among the team members.

- The information:

—Lends itself to various interpretations,

- Requires various kinds of expertise to be interpreted,

- May have various implications to the problem at hand, or

-Is of unknown quality, and requires evaluation before it can be used.

On the Organizational Analysis dimension-
- Most of the information they need is not documented.

- They are faced with making a decision that would have noticeable implications to the team's work.

Challenges to the CIR process are all part of the actors' dimension and they arise when:

- Actors have to spend time in discussions to achieve consensus among themselves.

- Actors have different stakes in the process, or have different priorities.

- Some actors are less familiar with the problem than others.

- It is necessary to decide which actors to involve in the CIR process, and how their expertise and experience would help decision-making.

- Much of the information is retrieved simultaneously by different actors.

- A CIR process is activated by an actor who is a novice and the other actors involved are experts.

- New ideas emerge during a CIR process and it is difficult to maintain focus among the actors.

This is only the beginning of our look into collaborative information retrieval. The purpose here is to present possible motivations and challenges to CIR, rather than aiming at predicting when and how CIR would occur and what challenges it would have to overcome.

The analysis here is of a single case, and other cases will have to be analyzed before we gain a comprehensive understanding of the motivation and challenges for CIR. Nevertheless, even at this early stage of the investigation, it is possible to illustrate how these findings can help in designing systems and services to support CIR. While it is too early to suggest any specific recommendations, it is possible to point to areas that could be addressed. This case shows, for instance, that a CIR event can become a forum for eliciting information from participants. This implies that acquiring information is an integral part of design work, and that CIR can serve social and organizational purposes as well. This suggests that information systems that are designed to support CIR should include mechanisms that support the interactions between the collaborating actors and enhance their access to one another's knowledge, ideas, and opinions or help them keep on track.

A study in a different context, and employing a different framework, arrived at the same recommendation. Reddy \& Dourish (2002) used the concept of "rhythms" (Zerubavel, 1979, Johnson-Lenz \& Johnson-Lenz, 1991) to analyze how individuals in a surgical intensive care unit coordinated information and work, the researchers concluded that the technologies for CIR and those for cooperative work should be intertwined, and not be designed to operate separately.

Similarly, to overcome an important challenge to CIR, systems and services could be designed to ease the cognitive overload that might be experienced during a CIR event. Studies of CIR in other situations will broaden and deepen our understanding of the phenomenon. This, in turn, will make it possible to arrive at more specific recommendations to guide the design of systems and services to support CIR. 


\section{Conclusions}

Human-information interaction is a complex phenomenon requiring complex analyses. To date, research about human-information behavior has been dominated by onedimensional approaches. While such approaches might have been necessary for the field during its initial steps, the time has come for the field to adopt approaches that consider several dimensions simultaneously. The Cognitive Work Analysis framework is one such approach that has been applied successfully in a variety of situations and proved highly effective in the analysis of CIR.

The case reported here demonstrated that various circumstances may motivate an actor to engage in collaborative information retrieval, some of which may also present challenges. Uncovering these motivations is essential to understanding the phenomenon. This requires investigations into several dimensions and an awareness of the ways in which factors in these dimensions interact with one another. This conclusion also applies to other topics of research in the study of human-information behavior. We believe, therefore, that employing multidimensional approaches such as Cognitive Work Analysis can enhance the study of human-information interaction.

\section{Acknowledgments}

Susan Dumais and Jonathan Grudin from Microsoft Research, as well as Steven Poltrock from Boeing, were also investigators on the CIR project. The team of the Project extends deepest gratitude to the engineers in both organizations who participated in the study. The Project would have not materialized without their cooperation. Other contributors were Martha Smith and Constance Daruthayan who supported the research team, and Jens-Erik Mai and Patricia Katopol who reviewed an earlier version of the manuscript. Two JASIST reviewers provided useful comments that helped to improve this paper. This material is based upon work supported by the National Science Foundation under Grant No. 9908138. Any opinions, findings, and conclusions or recommendations expressed in this material are those of the authors and do not necessarily reflect the views of the National Science Foundation.

\section{References}

Algon, J. (1996). Classification of tasks, steps, and information-related behaviors of individuals on project teams. In P. Vakkari, R. Savolainen, \& B. Dervin (Eds.), Information Seeking in Context: Proceedings of an International Conference on Research in Information Needs, Seeking and Use in Different Contexts (pp. 205-221). Cambridge, UK: Taylor Graham.

Allen, B. (1997). Information needs: A person-in-situation approach. In P. Vakkari, R. Savolainen, \& B. Dervin (Eds.), Information Seeking in Context: Proceedings of an International Conference on Research in Information Needs, Seeking and Use in Different Contexts (pp. 111122). Cambridge, UK: Taylor Graham.
Ancona, D.G., \& Caldwell, D.F. (1988). Beyond task and maintenance: Defining external functions in groups. Group and Organization Studies, 13(4), 468-494.

Ancona, D.G., \& Caldwell, D.F. (1992). Bridging the boundary: External activity and performance in organizational teams. Administrative Science Quarterly, 37, 634-665.

Baldwin, N.S., \& Rice, R.E. (1997). Information-seeking behavior of securities analysts: Individual and institutional influences, information sources and channels, and outcomes. Journal of the American Society for Information Science, 48(8), 674-693.

Bates, M.J. (1989). The design of browsing and berrypicking techniques for the online search interface. Online Review, 13, 407-424.

Belkin, N. (1980). Anomalous states of knowledge as a basis for information retrieval. Canadian Journal of Information Science, 5, 133-143.

Brown, M.E. (1991). A general model of information-seeking behavior. In J.-M. Griffiths (Ed.), Proceedings of the 54th American Society for Information Science (ASIS) Annual Meeting (Vol. 28, pp. 9-14). Medford, NJ: Learned Information.

Bruce, H.W. (1994). A cognitive view of the situational dynamism of user-centered relevance estimation. Journal of the American Society for Information Science, 45, 142-148.

Bruce, H., Fidel, R., Pejtersen, A., Dumais, S., Grudin, J., \& Poltrock, S. (2003). A comparison of the collaborative information retrieval (CIR) behaviours of two design teams. The New Review of Information Behaviour Research, 4, 139-153.

Bystrom, K., \& Jarvelin, K. (1995). Task complexity affects information seeking and use. Information Processing \& Management, 31, 191-213.

Chatman, E.A. (2000). Framing social life in theory and research. The New Review of Information Behaviour Research: Studies of Information Seeking in Context, 1, 3-17.

Choo, C.W., Detlor, B., \& Turnbull, D. (2000). Information seeking on the Web: An integrated model of browsing and searching. First Monday, 5(2). Retrieved from http://www.firstmonday.dk/issues/issue5_2/choo/ index.html

Cusumano, M.A., \& Selby, RW. (1998). Microsoft secrets: How the world's most powerful software company creates technology, shapes markets, and manages people. New York: Simon \& Schuster.

Dervin, B. (1992). From the mind's eye of the user: The sense-making qualitative-quantitative methodology. In J.D. Glazier \& R.R. Powell (Eds.), Qualitative research in information management (pp. 61-84). Englewood, CO: Libraries Unlimited.

Ellis, D. (1989). A behavioural approach to information retrieval design. Journal of Documentation, 45(3), 171-212.

Fidel, R. (2000). The user-centered approach: How we got here. In W.J. Wheeler (Ed.), Saving the time of the library user through subject access innovation: Papers in honor of Pauline Atherton Cochrane (pp. 79-99). Champaign, IL: Graduate School of Library and Information Science.

Fidel, R., Bruce, H.W., Pejtersen, A.M., Dumais, S., Grudin, J., \& Poltrock, S. (2001). Collaborative Information Retrieval (CIR). The New Review of Information Behaviour Research: Studies of Information Seeking in Context, 1, 235-247.

Fidel, R., Davies, R.K., Douglass, M.H., Holder, J.K., Hopkins, C.J., Kushner, E.J., Miyagishima, B.K., \& Toney, C.D. (1999). A visit to the information mall: Web searching behavior of high school students. Journal of the American Society of Information Science, 50(1), 24-37.

Ford, N., Miller, D., \& Moss, N. (2003). Web search strategies and approaches to studying. Journal of the American Society for Information Science and Technology, 54(6), 473-489.

Govindarej, T., Pejtersen, A.M., \& Carstensen, P. (1997). An information system based on empirical studies of engineering designers. Computational Cybernetics and Simulation, 1, 708-713.

Guinan, P.J., Cooprider, J.G., \& Faraj, S. (1998). Enabling software development team performance during requirements definition: A behavioral versus technical approach. Information Systems Research, 9(2), $101-125$.

Hertzum, M., Pejtersen, A.M., Cleal, B., \& Albrechtsen, H. (2002). An analysis of collaboration in three film archives. A case for collaboratories. In H. Bruce et al. (Eds.), Emerging Frameworks and Methods: 
Proceedings of the Fourth International Conference on Conceptions of Library and Information Science (pp. 69-84). Westport, CT: Libraries Unlimited.

Hjørland, B. (2003). Social and cultural awareness and responsibility in library, information and documentation studies. In B. Rayward, J. Hansson, \& V. Suominen (Eds.), Aware and Responsible: Papers presented at the Nordic and International Colloquium on Social and Cultural Awareness and Responsibility in Library, Information and Documentation Studies (SCARLID) (pp. 71-91). Lanham, MD: Scarecrow.

Johnson-Lenz, P., \& Johnson-Lenz, T. (1991). Post-mechanistic groupware primitives: Rhythm, boundaries, and containers. The International Journal of Man-Machine Studies, 34, 395-417.

Kuhlthau, C. (1991). Inside the search process: Information seeking from the user's perspective. Journal of the American Society for Information Science, 42(5), 361-371.

Lamb, R., \& Kling, R. (2003) Reconceptualizing users as social actors in information systems research. MIS Quarterly, 27(2), 197-235.

Leckie, G.J., Pettigrew, K.E., \& Sylvain, C. (1996). Modeling the information seeking of professionals: A general model derived from research on engineers, health care professionals, and lawyers. Library Quarterly, 66(2), 161-193.

Pejtersen, A.M. (1984). Design of a computer-aided user-system dialogue based on an analysis of users' search behaviour. Social Science Information Studies, 4(2/3), 167-183.

Pennanen, M., \& Vakkari, P. (2002). Students' cognition and information searching while preparing a research proposal. In H. Bruce et al. (Eds.), Emerging Frameworks and Methods: Proceedings of the Fourth International Conference on Conceptions of Library and Information Science (pp. 33-48). Westport, CT: Libraries Unlimited.

Paepcke, A. (1996). Information needs in technical work settings and their implications for the design of computer tools. Computer Supported Cooperative Work: The Journal of Collaborative Computing, 5(1), 6392.

Pettigrew, K.E. (1999). Waiting for chiropody: Contextual results from an ethnographic study of the information behavior among attendees at community clinics. Information Processing \& Management, 35(6), 801817.

Pettigrew, K.E. (2000). Lay information provision in community settings: How community health nurses disseminate human services information to the elderly. Library Quarterly, 70(1), 47-85.

Pettigrew, K.E., Fidel, R., \& Bruce, H. (2001). Conceptual frameworks in information behavior. Annual Review of Information Science and Technology (ARIST), 35, 43-78.

Poltrock, S., Grudin, J., Dumais, S., Fidel, R., Bruce, H., \& Pejtersen, A.M. (2003). Information seeking and sharing in design teams. In M. Pendergast, K. Schmidt, C. Simone, \& M. Tremaine (Eds.), Proceedings of the 2003 International ACM SIGGROUP Conference on Supporting Group Work (pp. 239-247). New York: ACM.

Rasmussen, J., Pejtersen, A.M., \& Goodstein, L.P. (1994). Cognitive systems engineering. New York: Wiley.

Reddy, M., \& Dourish, P. (2002). A finger on the pulse: Temporal rhythms and information seeking in medical work. Papers presented at ACM 2002 Conference on Computer Supported Cooperative Work (CSCW 2002) (pp. 344-353). New York: ACM.

Savolainen, R. (1995). Everyday life information seeking: Approaching information seeking in the context of 'Way of Life.' Library and Information Science Research, 17, 259-294.

SIG/USE. (2003). Measuring search behaviors: Current and proposed methods. Retrieved March 28, 2003, from http://www.asis.org/SIG/ SIGUSE/
Solomon, P. (1999) Information mosaics: Patterns of action that structure. In T.D. Wilson \& D.K. Allen (Eds.), Exploring the Contexts of Information Behaviour: Proceedings of the Second International Conference on Research in Information Needs, Seeking and Use in Different Contexts (pp. 150-175). London: Taylor Graham.

Sonnenwald, D.H. (1999). Evolving perspectives of human information behaviour: Contexts, situations, social networks and information horizons. In T.D. Wilson \& D.K. Allen (Eds.), Exploring the Contexts of Information Behaviour: Proceedings of the Second International Conference on Research in Information Needs, Seeking and Use in Different Contexts (pp. 197-204). London: Taylor Graham.

Sonnenwald, D.H., \& Lievrouw, L.A. (1996). Collaboration during the design process: A case study of communication, information behavior, and project performance. In P. Vakkari, R. Savolainen, \& B. Dervin (Eds.), Information Seeking in Context: Proceedings of an International Conference on Research in Information Needs, Seeking and Use in Different Contexts (pp. 205-221). Cambridge, UK: Taylor Graham.

Sonnenwald, D.H., \& Pierce, L.G. (2000). Information behaviour in dynamic group work contexts: Interwoven situational awareness, dense social networks and contested collaboration in command and control. Information Processing \& Management, 36(3), 461-479.

Sonnenwald, D.H., Wildemuth, B.M., Brassell, E., Kindon, V., \& Harmon, G. (2001). A research method to investigate information seeking using the concept of Information Horizons: An example from a study of lower socio-economic students' information seeking behavior. In L. Höglunr (Ed.), The New Review of Information Behaviour Research: Studies of Information Seeking in Context. Papers presented at Information Seeking in Context 2000: The Third International Conference on Information Needs, Seeking and Use in Different Contexts. London: Taylor Graham.

Talja, S., Keso, H., \& Pietilainen, T. (1999). The production of 'context' in information seeking research: A metatheoretical view. Information Processing \& Management, 35(6), 751-763.

Taylor, R.S. (1968) Question-negotiation and information seeking in libraries. College and Research Libraries, 29, 178-194.

Tuominen, K., \& Savolainen, R. (1997). A social constructionist approach to the study of information use as discursive action. In P. Vakkari, R. Savolainen, \& B. Dervin (Eds.), Information Seeking in Context: Proceedings of the International Conference on Research in Information Needs, Seeking and Use in Different Contexts (pp. 81-96). Cambridge, UK: Taylor Graham.

Vakkari, P. (1999). Task complexity, information types, search strategies and relevance: Integrating studies on information seeking and retrieval. In T.D. Wilson \& D.K. Allen (Eds.), Exploring the Contexts of Information Behaviour: Proceedings of the Second International Conference on Research in Information Needs, Seeking and Use in Different Contexts (pp. 35-54). Cambridge, UK: Taylor Graham.

Vakkari, P. (2003). Task-based information searching. Annual Review of Information Science and Technology (ARIST), 37, 413-466.

Vicente, K.J. (1999). Cognitive Work Analysis: Towards safe, productive, and healthy computer-based work. Mahwah, NJ: Erlbaum.

Williamson, K. (1998). Discovered by chance: The role of incidental information acquisition in an ecological model of information use. Library and Information Science Research, 20(1), 23-40.

Wilson, T.D. (1999). Models in information behaviour research. Journal of Documentation, 55(3), 249-270.

Yerbury, H., \& Parker, J. (1998). Novice searchers' use of familiar structures in searching bibliographic retrieval systems. Journal of Information Science, 24(4), 207-214

Zerubavel, E. (1979). Patterns of time in hospital life: A sociological perspective. Chicago: University of Chicago Press. 